\title{
An evaluation of scale-dependent effects of atmosphere-glacier interactions on heat supply to glaciers
}

\author{
Tetsuo Ohata \\ Water Research Institute, Nagoya University, Chikusa-ku, Nagoya 464-01, Japan
}

\begin{abstract}
Scale-dependent atmosphere-glacier interactions operate over a glacier surface as the surface has different thermal and radiative characteristics from those of the surrounding ground. In order to evaluate heat supply to the glacier surface in the main ablation period, three main interaction processes are considered: advection, glacier wind, and multiple reflection of solar radiation. The amount of heat supply was calculated for the equilibrium line altitude (ELA) by assuming a simple rectangular-shaped glacier, and by applying meteorological and glaciological data for four different glaciated regions (Tien Shan, Patagonia, west Kunlun and Nepal Himalaya). The total heat supply due to the above three processes had the common tendency of being smallest for glaciers of 1 to several kilometres in length, and largest at $16 \mathrm{~km}$, which was the maximum length considered in this study. Among the cases, the Tien Shan showed a daytime heat supply higher by $2.3 \mathrm{MJ} \mathrm{m}^{-2}$ for a $16 \mathrm{~km}$-long glacier compared with a small glacier $2 \mathrm{~km}$ in length. Relating this difference directly to ELA, an ELA approximately $300 \mathrm{~m}$ higher might be expected for a long glacier than a short one, assuming the same amount of solid precipitation. Glacier inventory data for China support this tendency, but the calculated value is slightly larger than that observed. The results show that there is a possibility that responses in glacier variation to climate change may be modified considerably through scale-dependent atmosphere-glacier interactions.
\end{abstract}

\section{INTRODUGTION}

An essential part in predicting glacier response to climatic warming or cooling, and in deducing former climatic factors from past glacier behaviour, is understanding how mass balance or mass-balance components vary with a climatic change. Mass balance can be separated into accumulation and ablation, the latter occurring through heat transfer processes (Kuhn, 1981, 1989). A glacier or snow/ice mass is constantly experiencing interaction with the atmosphere, and this has an effect on determining the heat transfer and, consequently, glacier mass balance.

Here, atmosphere-glacier interaction is defined as the group of atmospheric processes occurring due to the physical and morphological characteristics of glaciers, and the accumulated effect of these processes on mass balance and glacier fluctuations. This interaction between the glacier and local climate, as part of the climate-glacier relationship, has been cited in the literature (Paterson, 1981), but has not been clarified quantitatively. Oerlemans (1989) has addressed this problem by introducing the effect of advection. However, there are other processes related to the interaction between atmosphere and snow and ice surfaces.

In this paper, interactive processes affecting heat transfer to a glacier surface in the main ablation season will be examined and evaluated through consideration of the main atmospheric processes, in which glacier size is an essential parameter. The following three atmospheric processes are considered (Fig. 1).

1. The development of an internal boundary layer on a glacier due to advection. Due to this process (denoted as ADV) the air mass cools and sensible heat flux at the surface decreases with distance as the air flows over the glacier.

2. The occurrence of glacier winds. This process (denoted as GW) is a local wind on a glacier, which enhances sensible heat flux to the surface and increases circulation of the air.

3. Multiple reflection of solar radiation between the snow/ice surface and clouds. This process (denoted as MR) maintains higher downward solar radiation surfaces, such as snow, with higher albedos.

The first two are due to the physical characteristic that the melting point of snow and ice surfaces is $0^{\circ} \mathrm{C}$, and the third is due to the high albedo of the snow surface.

The aim of this study is to evaluate the possible effect of the three above-mentioned processes on glaciers of different sizes. Calculations are made for an idealized rectangular-shaped glacier lying on a slope with a 


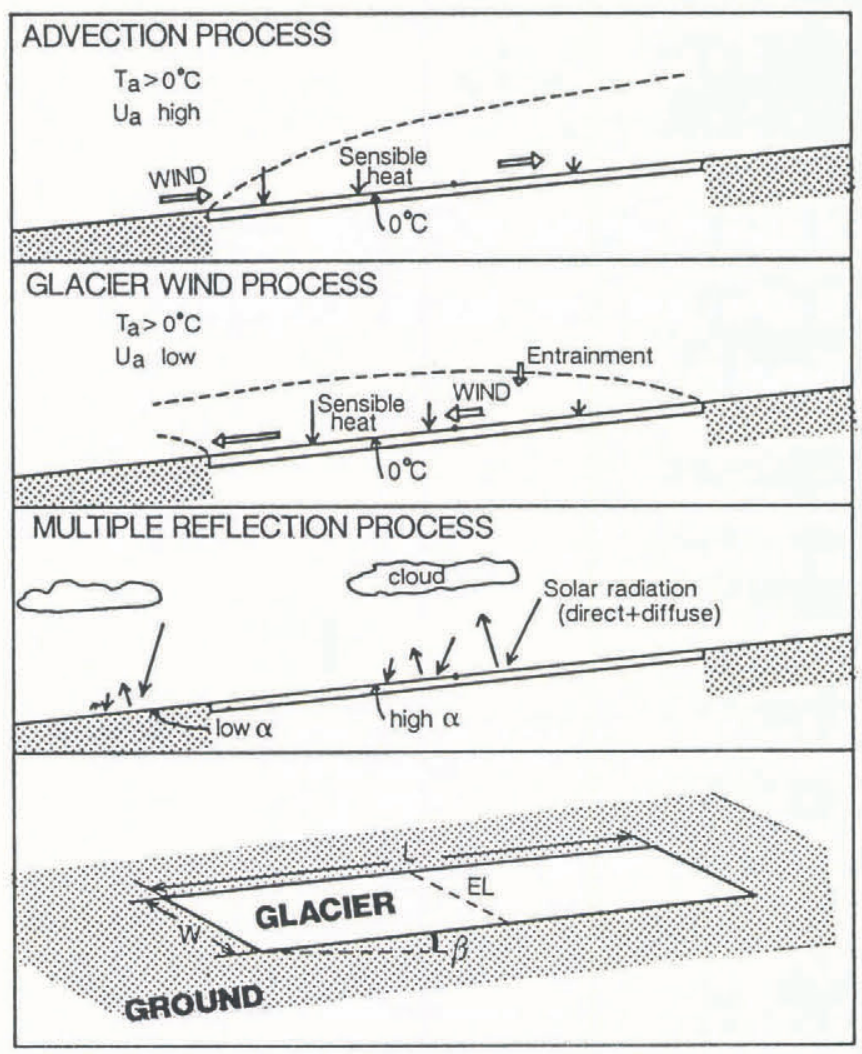

Fig. 1. Schematic diagram of the three atmospheric processes considered as the atmosphere-glacier interaction (top three), and the glacier geometry used in the calculations (bottom) for equilibrium line altitude (ELA) level. For explanations see text.

constant inclination (Fig. 1), length being $L$ and width $W$, which was taken to be one-fifth of the length. Calculations were made for sizes $L=0.25$ to $L=16 \mathrm{~km}$. Inclination of the surface and roughness of the surface were considered to be uniform. EL is considered to be situated at the middle of the glacier. Observed data during the main ablation period are used for estimating meteorological and glacier surface parameters. Calculations are made only for the equilibrium line altitude (ELA) level.

Actual meteorological and glaciological data are used for the experiment, observations being taken from the Tien Shan mountains and the west Kunlun mountains in western China, Shorong Himal in the central Nepal Himalayas and northern Patagonia in southern Chile.

\section{METHOD OF GALGULATION}

Point ablation on a glacier surface can be expressed by the heat balance equation. This is commonly formulated in the following equations:

$$
\begin{gathered}
Q_{\mathrm{NR}}+Q_{\mathrm{S}}+Q_{\mathrm{L}}+Q_{\mathrm{C}}+Q_{\mathrm{M}}=0, \\
Q_{\mathrm{NR}}=Q_{\mathrm{SW}}+Q_{\mathrm{LW}},
\end{gathered}
$$

and

$$
Q_{\mathrm{SW}}=Q_{\mathrm{SW} \downarrow}(1-a) .
$$

Symbols are as follows:

$\begin{aligned} Q_{\mathrm{NR}} & \text { net radiation } \\ Q_{\mathrm{SW}} & \text { net shortwave radiation } \\ Q_{\mathrm{LW}} & \text { net longwave radiation } \\ Q_{\mathrm{SW} \downarrow} & \text { downward shortwave radiation } \\ Q_{\mathrm{S}} & \text { sensible heat flux } \\ Q_{\mathrm{L}} & \text { latent heat flux } \\ Q_{\mathrm{C}} & \text { heat conduction into snow and ice } \\ Q_{\mathrm{M}} & \text { heat used for melting } \\ a & \text { surface albedo }\end{aligned}$

$Q_{\mathrm{C}}$ is usually small in the case of the main ablation period. $Q_{\mathrm{L}}$ is generally small, but can be large in some humid or extremely dry climate cases. However, there is only limited information on humidity on glaciers so this component is neglected in the present evaluation. $Q_{\mathrm{S}}$ can be written in general in the following form using in situ meteorological parameters:

$$
Q_{\mathrm{S}}=\rho \mathrm{C}_{\mathrm{p}} C_{\mathrm{h}}\left(T-T_{\mathrm{s}}\right)
$$

where $\rho$ is density of air, $\mathrm{C}_{\mathrm{p}}$ is specific heat of air, $C_{\mathrm{h}}$ is diffusion coefficient, $T$ is air temperature at a certain level above the surface and $T_{\mathrm{s}}$ is surface temperature. The variables and parameters which undergo strong modification through boundary layer processes, that is $\mathrm{ADV}$ and GW processes, are air temperature, humidity, wind speed and the resulting diffusion coefficients. The temperature drop due to the advective process on the glacier is frequently termed temperature jump.

The ADV process will be calculated through the formulae developed for the boundary layer on a flat surface by Weisman and Brutsaert (1973) and Weisman (1977), and corroborated and applied to field observations by Takahara and Higuchi (1985) and Higuchi (1987). The effect of slight inclination on glaciers is neglected here. Ambient air temperature $\left(T_{\mathrm{a}}\right)$, wind speed $\left(U_{\mathrm{a}}\right)$, length $(L)$, roughness length $\left(z_{0}\right)$ are the needed parameters.

The GW process is simulated by the method developed by Ohata (1989b). Analytical results concerning the influence of the glacier wind on heat supply and ablation are discussed elsewhere by Ohata (1991a). Ambient air temperature $\left(T_{\mathrm{a}}\right)$, vertical gradient of air temperature $\left(\partial T_{\mathrm{a}} / \partial z\right)$, inclination $(p)$, length $(L)$, roughness length $\left(z_{0}\right)$ are the needed parameters.

The term in the radiation budget most affected by the atmosphere-snow/ice interaction is the term $Q_{\mathrm{SW}}$, through the MR process. This depends on the areal surface albedo in relation to the distance between the surface to the height of the cloud base, so that geometry of the glacier is important. Other terms, such as downward longwave radiation, vary through changes in air temperature and vapour pressure brought about by advection, but this term will not be treated here.

The MR process is calculated according to Ohata (1991b):

$$
Q_{\mathrm{sw} \downarrow}=\frac{(1-n+\tau n)}{(1-\bar{a} \gamma n)} I_{0} .
$$


Notation of symbols is as follows:

$I_{0} \quad$ incident global solar radiation above the cloud

$n$ cloud amount $(0-1)$

$\gamma$ reflection coefficient of the cloud $(0-1)$

$\tau$ transmission coefficient of the cloud $(0-1)$

$\bar{a} \quad$ areal mean surface albedo

From the definition of the involved quantities,

$$
\alpha+\gamma+\tau=1
$$

where $\alpha$ is the absorption coefficient. $\bar{a}$ was calculated for a circular area of glacier with diameter equal to the mean height of cloud base.

The present calculation involves the heat fluxes due to the three processes mentioned above for the main ablation period within the ablation season. The surface conditions and other data are taken near the ELA or around the glaciers under present conditions and dimensions. In the following sections, it is assumed that the amount of solid precipitation does not depend much on altitude for glaciers small in area. Thus, variation in heat supply at ELA level when the elevation of the ELA is changed can be directly related to the change in height of the ELA.

\section{METEOROLOGIGAL AND GLAGIOLOGIGAL DATA}

Four glacierized areas are considered. Parameters needed for estimation of the ADV, GW and MR processes are listed in Table 1.
As for meteorological variables, hourly mean values of the actual observed values were taken and these were used for calculating ADV and GW. Wind was assumed to blow down-glacier, though this was not actually always the case.

As for calculating the heat flux arising through the MR process, daytime mean values were used for all parameters as data were not available on an hourly basis. Mean cloud base height was taken to be constant, at $1 \mathrm{~km}$ in all cases.

Calculations were made for those hours when melting could be assumed, that is, when $Q_{\mathrm{SW} \downarrow}$ was positive and $T$ was above $0^{\circ} \mathrm{C}$. In most cases, the period was 12 hours, but sometimes it was 1 or 2 hours shorter, so that the values of the various heat fluxes given here are for the daytime.

\section{RESULTS AND DISCUSSION}

\subsection{Calculation results}

The results of calculations of $Q_{\mathrm{SW}}$ and $Q_{\mathrm{S}}$ taking $\mathrm{MR}$ $\left(Q_{\mathrm{MR}}\right), \mathrm{ADV}\left(Q_{\mathrm{ADV}}\right)$ and $\mathrm{GW}\left(Q_{\mathrm{GW}}\right)$ processes into consideration are shown in Figure 2, both in relation to glacier length, and as "standard value" which is independent of glacier size. These "standard" values $\left((Q)_{\mathrm{ST}}\right)$ were calculated as follows:

$$
\left(Q_{\mathrm{SW}}\right)_{\mathrm{ST}}=\left(Q_{\mathrm{SW} \downarrow}\right)_{\mathrm{G}}\left(1-a_{\mathrm{ELA}}\right),
$$

and

$$
\left(Q_{S}\right)_{S T}=\rho \mathrm{k}^{2} \frac{U_{\mathrm{a}} T_{\mathrm{a}}}{\ln ^{2}\left(\frac{Z_{\mathrm{a}}}{Z_{0}}\right)},
$$

Table 1. Meteorological and glaciological parameters used in the present calculation. $\bar{T}_{\mathrm{a}}$ and $\bar{U}_{\mathrm{a}}$ are daytime mean temperature and wind speed of ambient air, respectively

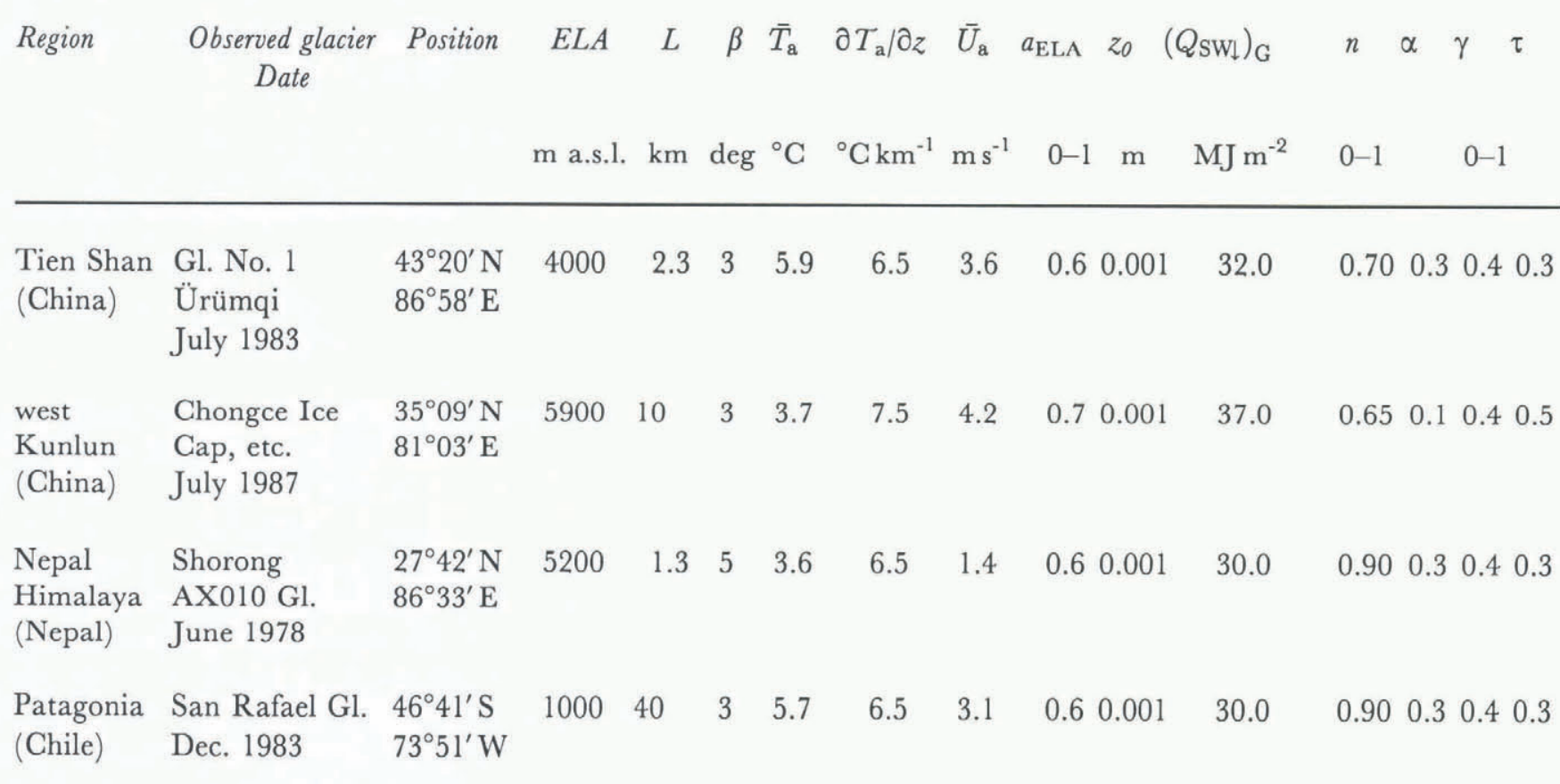



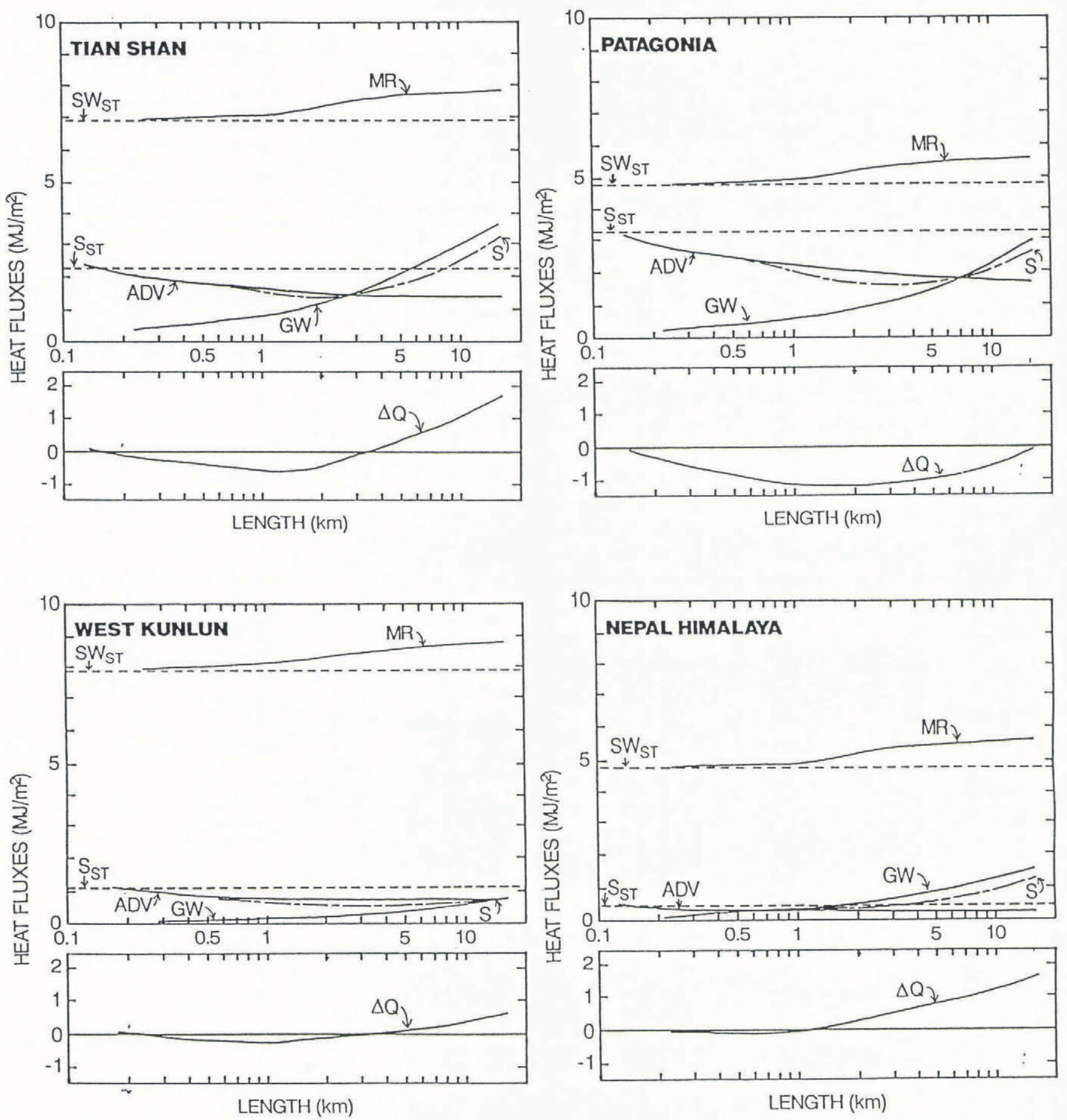

Fig. 2. The relation between heat fluxes due to three atmospheric processes ( $M R, A D V, G W$ processes), standard values, $\left(\left(Q_{\mathrm{SW}}\right)_{\mathrm{ST}}\right.$ and $\left.\left(Q_{\mathrm{S}}\right)_{\mathrm{ST}}\right)$ and deviation of total fluxes from sum of standard values, $\Delta Q$, for the daytime, and length of glacier, based on mean condition of the main ablation season. Length (horizontal axis) is taken in a logarithmic scale. Each symbol in the upper part of the figure is shortened by abbreviating $Q$.

where $\left(Q_{\mathrm{SW} \downarrow}\right)_{\mathrm{G}}$ is global solar radiation on the ground surface, $a_{\mathrm{ELA}}$ is surface albedo at ELA level, $k$ is the von Karman constant, $U_{a}, T_{a}$ and $z_{\mathrm{a}}$ are wind speed, ambient air temperature and the height at which they are observed. $z_{0}$ is roughness length. The standard value for $Q_{\mathrm{SW}},\left(Q_{\mathrm{SW}}\right)_{\mathrm{ST}}$ is obtained from incoming shortwave radiation $Q_{\mathrm{SW}}$ for the ground surface albedo value $(a=0.2)$ and absorption by ELA snow albedo $a_{\mathrm{ELA}}$ (shown by $S W_{\mathrm{ST}}$ in Figure 2). This can be considered as the value of $Q_{\mathrm{SW}}$ as $L \rightarrow 0$. The "standard value" for $Q_{\mathrm{S}}$, $\left(Q_{\mathrm{S}}\right)_{\mathrm{ST}}$, is the calculated heat flux using the value of ambient air temperature at the ELA and representative wind speed at $1.5 \mathrm{~m}$ level $\left(U_{a}\right)$, which was generally observed down-valley of the glacier.

The results show certain similarities for the four glacierized regions because of the ways each of the three processes work. One common characteristic is the increase of $Q_{\mathrm{MR}}$ as the glacier size increases, rising most steeply where the width of the glacier is nearly equal to the distance to the cloud base (fixed at $1 \mathrm{~km}$ ). The second common characteristic is that $Q_{\mathrm{ADV}}$ first declines before stabilizing at higher values of $L$, as $L$ increases. The third 
common characteristic is the near monotonic increase in $Q_{\mathrm{GW}}$ as $L$ increases. The four glacierized areas, however, differ in absolute value and rates of decrease and increase of each process. Absolute increases with size due to $Q_{\mathrm{MR}}$ are similar in the four areas between 0.8 and $-1.0 \mathrm{MJ} \mathrm{m}^{-2}$. By contrast, the decrease in $Q_{\mathrm{ADV}}$ is larger in warmer environments (Table 1 ), which mean high $\left(Q_{\mathrm{S}}\right)_{\mathrm{ST}}$. The same is true for the increase in $Q_{\mathrm{GW}}$.

$Q_{\text {ADV }}$ increases above the "standard value" at the very small scale, which is usually smaller than the size of the glacier as all the area of snow and ice is within a short distance of the snowfield margin. This may mean that melting of a snow and ice mass will accelerate after it has become smaller than $200 \mathrm{~m}$ or so.

Before calculating the total heat supply of all three of the processes, it must be noted that $Q_{\mathrm{ADV}}$ and $Q_{\mathrm{GW}}$ cannot occur at the same time, and so the frequency of the ADV and GW processes must be assumed. Ohata (1991a) stated that frequency of occurrence of glacier wind is higher for glaciers in warmer environments and for larger glaciers. Frequency of glacier winds is determined through quite complicated processes, which are not easily predicted.

Here, it is assumed that frequency of glacier wind depends solely on glacier size. From a few observations on glaciers (Ohata,1991a), a high frequency (80-90\%) of glacier wind was observed on a large glacier several tens of square kilometres in area. Relatively frequent glacier winds have been observed on glaciers of a few square kilometres (DES, 1969; Streten and Wendler, 1967), and a lower frequency on glaciers of approximately $1 \mathrm{~km}$ or less (Ohata, 1991a). Therefore, a frequency factor, $f(L)$, for glacier wind is taken to be $80 \%$ at $L=16 \mathrm{~km}$ and $0 \%$ at $L=0.5 \mathrm{~km}$, changing logarithmically with increases in $L$ (Fig. 3). Total sensible heat supply, $Q_{\mathrm{S}}$, calculated according to the above assumption is shown in Figure 2 as S.

The total heat supply due to the three processes is shown in Figure 2 by the deviation $\Delta Q$, from the sum of the two "standard values". It can be seen that the shape of the curve of $\Delta Q$ against $L$ varies between the different glacierized areas. However, a general tendency is that $\Delta Q$ reaches a minimum at a parameter $L$ and then increases. This is the result of the three competing processes. Lower heat supply variously appears at a certain scale between 0.5 and $3 \mathrm{~km}$ in length. The strongest lowering of $\Delta Q$ is in Patagonia, due to the large decline in $Q_{\mathrm{ADV}}$. There is little reduction of $\Delta Q$ in the cold environments of Shorong Himalaya and west Kunlun, the Tien Shan being intermediate.

In order to make a quantitative evaluation of the impact of glacier size on heat balance, the difference

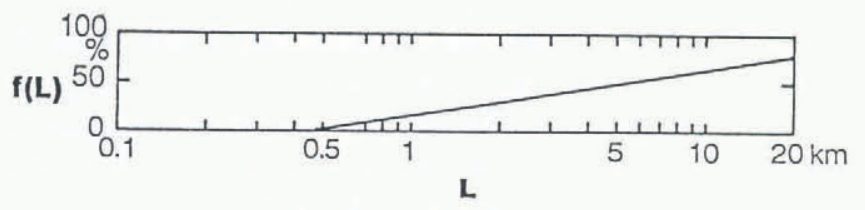

Fig. 3. The form of function $f(L)$, the frequency of occurrence of $G W$ process as a percentage, in relation to glacier length. between the minimum value and the maximum value taken at $L=16 \mathrm{~km},\left((\Delta Q)_{\mathrm{MM}}\right)$, is examined. The largest $(\Delta Q)_{\mathrm{MM}}$ occurs in the Tien Shan, with a value of about $2.3 \mathrm{MJ} \mathrm{m}^{-2}$, and the lowest in the Shorong Himalaya of $0.9 \mathrm{MJ} \mathrm{m}^{-2}$. The amount of $2.3 \mathrm{MJ} \mathrm{m}^{-2}$ under Tien Shan conditions is equivalent to $35 \%$ of the total heat used for melting on the ideal glacier during the observation period (Ohata and others, 1989). Under Tien Shan conditions interaction between the processes would seem to increase supplied heat the most for large-scale glaciers. Meteorological conditions favouring a large $(\Delta Q)_{\mathrm{MM}}$ in this glacierized range seem to be warm conditions with moderate wind speeds. In the case of a warm region with strong winds, such as Patagonia, the effect of the ADV process predominates, maintaining low $\Delta Q$ up to the larger sizes.

The results obtained above are calculations for the main ablation period. The general trend of the curve $\Delta Q$ for the whole ablation period is expected to be flatter than the curves in Figure 2, as it will be influenced by days having lower air temperatures.

The heat fluxes calculated for $L=16 \mathrm{~km}$ with lower air temperatures indicate that $\Delta Q$ will be similar to that for $L=1.5 \mathrm{~km}$, when the ambient air temperature is $2^{\circ} \mathrm{C}$ lower, equivalent to approximately $300 \mathrm{~m}$ higher elevation assuming a lapse rate of $6.5^{\circ} \mathrm{C} \mathrm{km}^{-1}$.

This result means that a large ice mass of length $16 \mathrm{~km}$ or more in the same region as a small 1 to $2 \mathrm{~km}$ size glacier under the same ambient climatic conditions, with the same amount of solid-phase precipitation, would have an ELA higher by nearly $300 \mathrm{~m}$.

\subsection{Statistical analysis of the ELAs of glaciers of different sizes}

If the processes described do determine the ELA, the tendency of ELA to be higher on larger glaciers should be evident in a statistical analysis of the elevation of the ELA on glaciers in an area where ambient atmospheric conditions can be considered to be the same.

Glacier inventory data can be used for checking this point. Fortunately, there are detailed inventories of the glaciers of the Qilian mountains and Tien Shan mountains in China (Wang, 1981; LIGG, 1986a, b, c, 1987). In order to investigate the relation between the length of a glacier and the ELA, deviations, $\Delta h$, of $h_{\mathrm{ELA}}$, the equilibrium-line deviation of each glacier in a drainage area from the mean ELA $\bar{h}_{\mathrm{ELA}}$ of the area, are taken:

$$
\Delta h=\left(h_{\mathrm{ELA}}-\bar{h}_{\mathrm{ELA}}\right) .
$$

ELAs are given for less than $10 \%$ of the glaciers in the inventories. The following conditions also had to be met in selecting glaciers: (1) drainage basins having fewer than 40 recorded glaciers, but where the ELA is given for more than six glaciers and (2) omission of glaciers with a south-facing aspect.

The first condition was set to eliminate large drainage basins within which ambient climate conditions might vary within one drainage area, and to limit the error arising from a small sample number. The second condition was set in order to examine clearly the relation between ELA and the length of glacier. South-facing 


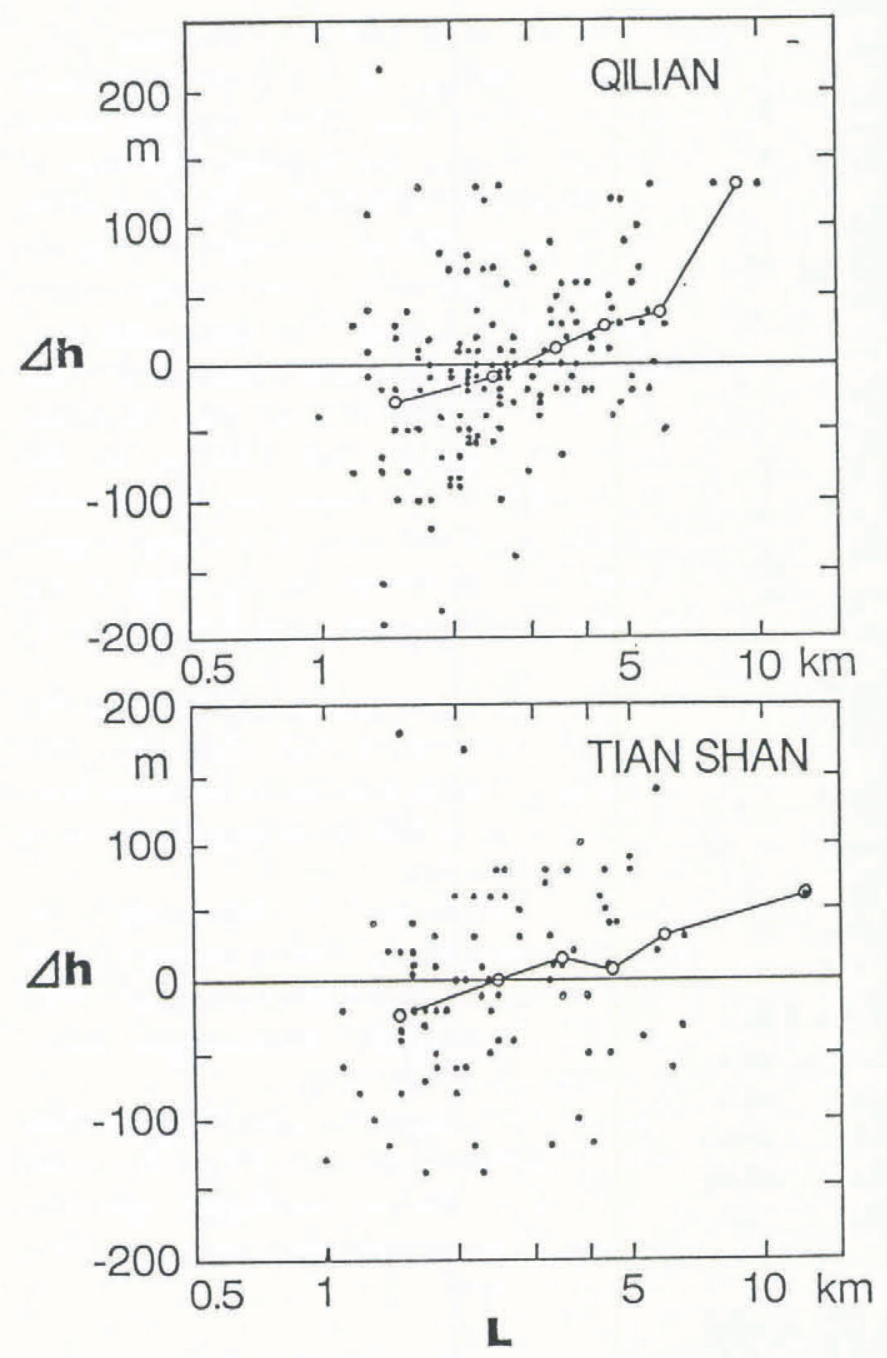

Fig. 4. The relation of ELA deviation, $\Delta h$, and glacier length, L, at Qilian mountains and Tien Shan mountains, western China. Glacier length (horizontal axis) is taken in a logarithmic scale.

glaciers have particularly high ELAs because of topographical conditions, and are generally short. This elimination should not affect the purpose of the present analysis.

$\Delta h$ for each glacier selected is shown in relation to glacier length, $L$, for the Tien Shan and the Qilian in Figure 4. The mean values of $\Delta h$ for six classes of glacier length ( 1 to $1.9 \mathrm{~km}, 2$ to $2.9 \mathrm{~km}, 3$ to $3.9 \mathrm{~km}, 4$ to $4.9 \mathrm{~km}, 5$ to $6.9 \mathrm{~km}$ and $7 \mathrm{~km}$ and over) are also shown in Figure 4. The mean lengths of glaciers in each drainage basin ranged between 1.5 to $4.7 \mathrm{~km}$ for the Tien Shan, and 2.0 to $4.1 \mathrm{~km}$ for the Qilian, so that the $\Delta h=0$ value corresponds to slightly different mean glacier lengths amongst the drainage basins. This statistical unevenness has a tendency to decrease the gradient of the curve.

Although the individual points are widely scattered, mean values for the six classes show increases in $\Delta h$ from the 1 to $2 \mathrm{~km}$ class to the $7 \mathrm{~km}$ class in both regions. The difference in mean $\Delta h$ between the 1 to $2 \mathrm{~km}$ and over $7 \mathrm{~km}$ classes for the Tien Shan is $75 \mathrm{~m}$, and for the Qilian $150 \mathrm{~m} . \Delta Q$ for the Tien Shan (in Fig. 2) indicates that a $1.5 \mathrm{MJ} \mathrm{m}^{-2}$ difference would be expected between glaciers of these lengths, equivalent to nearly $200 \mathrm{~m}$ difference in
ELA. The statistical analysis suggests a little less than this but not so apart. Thus, the statistical analysis supports the possibility of a scale effect on ELA through atmosphereglacier interaction, although other factors such as surrounding landforms may influence the actual distribution.

\subsection{Impact of the scale effect on glacier response to climate change}

These results show only the behaviour of the heat supply to ideal glaciers of various sizes under present climate conditions, and cannot be extended directly to estimate the variation or response of particular glaciers to climate change. However, if it is assumed that the only climatic variable changed is air temperature, then, within the same mountain range, these results can be used for prediction.

In the Tien Shan if a glacier extended from 1.5 to $16 \mathrm{~km}$ (equivalent to a lowering of ELA of between 500 and $700 \mathrm{~m}$, assuming that a $100 \mathrm{~m}$ change of ELA corresponds to lowering of 0.6 to $0.8^{\circ} \mathrm{C}$ (Kuhn, 1981) in ambient air temperature), such surface extension will receive heat supply almost equivalent to that which would raise ELA by nearly $300 \mathrm{~m}$. This means that nearly half of the expected ELA lowering arising from changed ambient air temperature conditions will be compensated by the scale effect of atmosphere-glacier interaction processes. This value may be a little high on account of the use in the calculations of data from the main ablation period. This result shows that to obtain 200 to $400 \mathrm{~m}$ lowering of ELA of a glacier of length $1.5 \mathrm{~km}$ requires a $4^{\circ} \mathrm{C}$ lowering of ambient air temperature.

\section{CONCLUDING REMARKS}

A particular parameterization for these scale-related processes was used in this study. The use of different parameterizations of the three processes would lead to different forms of $\Delta Q$. Whilst absolute quantities associated with each process probably depend on the parameterization, the general tendency will be similar. Therefore, the general characteristics of the present results will probably not be influenced by the method of parameterization.

The evaluation here was made specifically for the ELA level, but will probably reflect qualitatively atmosphere-ice interactions over the whole glacier. For example, in the ablation area the MR process will not occur in the same way as at the ELA since surface albedo is lower but the GW process will be enhanced as fetch length is increased. So the general tendency will not differ so greatly between the ablation area and the ELA level. Changes in ELA resulting from changes in ambient air temperatures can clearly be compensated or accentuated by scale-dependent atmosphere-glacier interaction processes. Furthermore, nonlinearity in the relationship between $\Delta Q$ and glacier length (Fig. 2) may produce nonlinearity in climate-glacier relationships.

The results obtained here provide a primary evaluation considering several atmospheric processes, and suggest the need for further study of this subject. If the 
processes envisaged here are operating, climate-glacier relationships such as those linking former ELA or glacier sizes with past environments will need to be re-evaluated.

The present study has considered the main processes only. There are other processes and parameters which depend on scales which require evaluation and other conditions which need to be investigated. These include:

1. The neglected effect of longwave radiation, similar to the ADV process.

2. Scale effects of latent heat flux are complex and will work in both ways, heat supply to and heat loss from the melting surface depending on humidity.

3. Surface parameters on the glacier, albedo, $a$, and roughness, $z_{0}$, may change according to the scale of the glacier. In this study, albedo at the ELA was held constant (in Equation (3)). However, albedo probably varies among glaciers, as inclusions darkening the snow cover frequently come from nearly bare ground, average distance $\mathrm{k}$, which depends upon the size of the glacier. Qualitatively, albedo will increase $\Delta Q$ in small-scale areal extent of, say, less than $1 \mathrm{~km}$ or so. As for roughness length, there may be a relationship such as large glacier tends to high glacier flow and greater surface roughness.

4. Other interactions such as size-ablation feedback, as changes in the wind system around the valley will result during glacier size change. Qualitatively, this will appear to weaken the effect of the ADV process.

5. Glacier size may itself affect the amount of the accumulation through variation in precipitation processes in certain climatic regions, for example in equatorial and subtropical regions.

6. Glaciers do not exist in the mountains independently but occur as groups of glaciers. This means that change in climate in a mountain area is intensified by changes in other glaciers, so that, in order to examine the variation of a certain glacier in relation to real "ambient climate", modification of mountain climate by the group of glaciers must also be evaluated.

In relating heat supply at ELA level to scaledependent ELA variation, climatic observations relating only to the main ablation period were used in this study. Calculations are necessary for the whole ablation period as the parameters used are subject to seasonal variation.

For more precise results, there is, primarily, a need for further data collection, to allow evaluation of other potential processes. Then, simultaneous observations on several glaciers of different scales in a small area where climate conditions can be considered to be uniform are essential to clarify the total effect of scale-dependent processes. Lastly, there is a need to develop a more sophisticated combined atmosphere-glacier variation model, so that all of these processes can be incorporated and simulated. In this context, three-dimensional regional atmospheric models incorporating the topography may be suitable for studies over long time periods.

\section{REFERENGES}

Higuchi, K. 1987. Study on the interaction of snow area through atmosphere. Nagoya University, Scientific Fund. (Re- search Report 1986.)

Kuhn, M. 1981. Climate and glaciers. International Association of Hydrological Sciences Publication 131 (Symposium at Canberra 1979 - Sea Level, Ice and Climatic Change), 3-20.

Kuhn, M. 1989. The response of the equilibrium line altitude to climate fluctuations: theory and observations. In Oerlemans, J., ed. Glacier fluctuations and climatic change. Proceedings of the Symposium on Glacier Fluctuations and Climatic Change, held in Amsterdam, 1-5 June 1987. Dordrecht, etc., Kluwer Academic Publishers, 407417.

Lanzhou Institute of Glaciology and Geocryology. 1986a. Glacier inventory of China. III. Tien Shan mountains (Ili River drainage basin). Beijing, Science Press.

Lanzhou Institute of Glaciology and Geocryology. 1986b. Glacier inventory of China. III. Tien Shan mountains (interior drainage area of Junggar Basin in northwest). Beijing, Science Press.

Lanzhou Institute of Glaciology and Geocryology. 1986c. Glacier inventory of China. III. Tien Shan mountains (interior drainage area of scattered flow in east). Beijing, Science Press.

Lanzhou Institute of Glaciology and Geocryology. 1987. Glacier inventory of China. III. Tien Shan mountains (interior drainage area of Tarim Basin in southwest). Beijing, Science Press.

Nationalkomitee für Geodäsie und Geophysik der Deutschen Demokratischen Republik. 1969. Die wissenschaftlichen Ergebnisse der deutschen Spitzbergenexpedition 1964-65. Teil 3. Die meteorologischen und hydrologischen Untersuchungen am Mittleren Lovéngletscher. Geodätische und Geophysikalische Veröffentlichungen, 2(12).

Oerlemans, J. 1989. On the response of valley glaciers to climatic change. In Oerlemans, J., eú. Glacier fluctuations and climatic change. Proceedings of the Symposium on Glacier Fluctuations and Climatic Change, held in Amsterdam, 1-5 June 1987. Dordrecht, etc., Kluwer Academic Publishers, 353-371.

Ohata, T. 1989a. Katabatic wind on melting snow and ice surfaces. (I.) Stationary glacier wind on a large maritime glacier. 7. Meteorol. Soc. Jpn., 67(1), 99-112.

Ohata, T. 1989b. Katabatic wind on melting snow and ice surfaces. (II.) Application of a theoretical model. $\mathcal{J}$. Meteorol. Soc. Jpn., 67(1), 113-122.

Ohata, T. 1991. The effect of glacier wind on local climate, turbulent heat fluxes and ablation. $Z$. Gletscherkd. Glazialgeol., 25(1), 49-68.

Ohata, T. In press. Effect of snow/ice-cloud radiative interaction on the global solar radiation at the surface of snow and ice masses. International Association of Hydrological Sciences Publication.

Ohata, T., Bai Zhongyuan and Ding Liangfu. 1989. Development of local climate in the glaciated area in the head of Urumqi River. F. Glaciol. Geocryol., 11(4), 325-334.

Paterson, W.S.B. 1981. The physics of glaciers. Second edition. Oxford, etc., Pergamon Press.

Streten, N.A. and G. Wendler. 1968. Some observations of Alaskan glacier winds in midsummer. Arctic, 21(2), 98-102.

Takahara, H. and K. Higuchi. 1985. Thermal modific- 
ation of air moving over melting snow surfaces. Ann. Glaciol., 6, 235-237.

Wang, Z. 1981. Glacier inventory of China. I. Qilian mountains. Lanzhou, Lanzhou Institute of Glaciology and Cryopedology.

Weisman, R.N. 1977. Snowmelt: a two-dimensional turbulent diffusion model. Water Resour. Res., 13(2),
337-342.

Weisman, R.N. and W. Brutsaert. 1973. Evaporation and cooling of a lake under unstable atmospheric conditions. Water Resour. Res., 9, 1242-1257.

The accuracy of references in the text and in this list is the responsibility of the author/s, to whom queries should be addressed. 